\title{
ИСПОЛЬЗОВАНИЕ ПСИХОЛОГИЧЕСКИХ ЗНАНИЙ ПРИ РАССЛЕДОВАНИИ УБИЙСТВ, СОВЕРШЕННЫХ НА БЫТОВОЙ ПОЧВЕ
}

\author{
Киселев Александр Петрович
}

В настоящей статье затрагиваются актуальные вопросы правоприменительной практики по расследованию наиболее социально опасных видов преступлений - бытовых убийств, составляющих значительную долю от общего количества совершенных на территории Российской Федерации случаев умышленного лишения жизни другого человека.

Эффективное расследование убийств, совершенных на бытовой почве, реализачия уполномоченными государственными органами комплекса мер, направленных на предупреждение совершения новых преступлений указанного вида, невозможны без знаний правоприменителем психологических особенностей такой личности. Проведенное научное исследование позволило выделить и обобщить данные особенности, раскрыть их содержание.

В статье дается понятие психологическим особенностям личности, совершившей бытовое убийство, приводятся мнения ученых, занимавшихся разработкой, изучением и исследованием данных направлений, указывается о психических аномалиях, их значении и влиянии на противоправное поведение личности, совершившей бытовое убийство. Сделана попытка указать причины, которые приводят или могут привести к совершению актов агрессии в семье, а также обозначить иные внешние обстоятельства, субъективные факторы, влияющие на выбор насильственного способа разрешения конфликта. Приведены особенности поведения бытового убийцы после совершения общественно опасного деяния.

В статье использованы не только эмпирические данные, но и данные, полученные из следственной и судебной практики, что позволило соединить практический опыт с психологическими, криминологическими исследованиями личности, применительно к бытовым убийствам. В связи с этим, статья представит как научный, так и практический интерес для специалистов, так или иначе задействованных в расследовании бытовых убийств, в их профилактике и предупреждении.

Ключевые слова: бытовые убийства, психологические особенности, психические аномалии, личность, психотравмирующая ситуачия, конфликтная ситуация, агрессия, мотивация, потребности, психологическая характеристика. 
Под психологическими особенностями личности понимается относительно стабильная совокупность индивидуальных качеств, определяющих типичные формы реагирования и адаптивные механизмы поведения, систему представлений о себе, межличностные отношения и характер социального взаимодействия. Другими словами, - это внутренний компонент личности, который представляет собой относительно устойчивую и неповторимую структуру, обеспечивающую индивиду активную деятельность в обществе $[4$, с. 28].

Каждая личность уникальна. В отдельном общественно опасном деянии нельзя абсолютизировать какие-то ее преступные особенности. Однако у каждого преступника можно обнаружить то общее, что характерно для всех преступников определенной категории. Как справедливо отмечено К. Е. Игогиевым, «какая бы конкретная личность ни изучалась, какой бы вид преступной деятельности ни рассматривался, во всех случаях, как во всяком отдельном, единичном, в них обнаруживаются черты и свойства общего порядка, входящие в характеристику преступника как социального типа» $[14$, с. 41].

«Криминалистическая классификация не может быть осуществлена в отрыве от общепсихологической классификации личности, поскольку не существует каких-либо особых "преступных черт" в психике человека» [5, с. 10]. Тем не менее, автор постарается выделить психологические особенности, присущие только рассматриваемому типу убийц.

Личность лица, совершившего наиболее опасное преступление против жизни и здоровья, весьма неординарна и теснейшим образом связана с его психологическими установками, отличающими его от людей, совершивших другие преступления, ведь в данном случае бытовой убийца посягает на самое незыблемое и дорогое в мироздании - жизнь человека.

«В условиях конфликтной либо длительной психотравмирующей ситуации у лица, совершившего бытовое убийство, всегда имеется выбор в средствах его разрешения. Последние (средства разрешения конфликта) могут иметь ненасильственный либо, напротив, насильственный характер. В первом случае конфликтная ситуация урегулируется путем ее избегания, разговора, перемирия. Во втором случае потерпевшему могут быть нанесены телесные повреждения различной степени тяжести (совместимые с жизнью). Таким образом, у человека всегда есть выбор в наборе сил и средств для выхода из сложившейся ситуации. Нет выбора - нет и преступления» [4, с. 147].

Безусловно, такие личности, в отличие от тех, которые прибегли к иным способам улаживания проблемы, имеют ряд своих психологических особенностей. Чтобы выявить эти особенности, провести между ними взаимосвязь, необходимо вникнуть в суть каждого конфликта, приведшего к лишению 
жизни, изучить его природу, понять, чем руководствовалась та или иная его сторона. Так что же толкает человека на выбор наиболее общественно опасного способа решения бытового конфликта? Данный вопрос представлял определенный интерес для изучения, но в силу тех или иных причин не является должным образом проработанным. Определенные шаги в данном направлении предпринимались Ю. М. Антоняном, И. В. Горшковым и Р. М. Зулкарнеевым. По мнению этих исследователей, «что касается причин убийств родственников и супругов, то их очевидность всегда лишь кажущаяся, они лежат в глубинных сферах человеческой психики и чаще всего, если иметь в виду мотивы, не охватываются сознанием. В то же время эти причины во всех случаях связаны с психотравмирующими переживаниями, с представлением индивида о самом себе, с его самоприятием, с его заботами и тревогами о своем биологическом и межличностном статусе. Понять причины подобных преступлений сложно, поскольку даже сами действующие субъекты, как правило, не в состоянии пояснить, что на самом деле толкало их на постоянные ссоры и даже драки со своими близкими, почему сложились такие отношения и почему они решились на роковой шаг. Они не могут понять происшедшие события и после того, как убийство уже совершено. Эмоциональный шок после преступления настолько велик, что внимание переключается на самого себя и защиту своих интересов в ходе ведущегося следствия или судебного разбирательства - все это, естественно, мешает здравому осмыслению и трезвой оценке случившегося» [3, с. 5].

Не акцентируя внимание на процессе доказывания, занятой позиции обвиняемого на предварительном следствии, касаемо его отношения к вине, такие лица не считают свое поведение основной причиной произошедшего, а уповают на межличностные (внутрисемейные) конфликты, виновником которых на протяжении длительного времени являлся потерпевший. Несмотря на данное обстоятельство, в ходе предварительного следствия обвиняемый, занявший такую позицию, может полностью признать свою вину в содеянном, искренне переживая за наступившие последствия.

«Систематические переживания будущими убийцами различных психотравмирующих ситуаций генерировали у них чувство обиды, злобы, раздражения; происходила аккумуляция эмоционального напряжения, которая в момент совершения преступления выполняла роль закручивающейся пружины и становилась движущей силой» [3, с. 6].

Как показывает практика, убийства, совершаемые в ходе ссоры либо иной напряженной конфликтной ситуации, составляют значительную долю убийств, совершенных на бытовой почве. Таким образом, в ходе бытового конфликта затрагиваются либо умаляются личные чувства обвиняемого, который для их восстановления, преследуя акт возмездия, выбирает насильственный 
способ. Этим наглядно демонстрируются такие качества бытового убийцы, как: ранимость, склонность к актам агрессии, преобладание возбудимости над тормозными процессами психики, слабый самоконтроль. В борьбе между сознанием и эмоциями победу непременно одерживают вторые, хотя первое при этом сохраняет способность осознавать всю суть происходящего.

В этой связи совершенно справедливо мнение А. И. Башкирского о том, что «на уровне личности преступления выступают как результат деформации некоторых звеньев индивидуально-психологического процесса мотивации и принятия решений. Это приводит к тому, что некоторые жизненные планы личности или ее реакция на конкретную жизненную ситуацию становятся неадекватными, не соответствуют линии поведения, принятой в обществе. Преступники характеризуются более высоким уровнем импульсивности, склонностью действовать по первому побуждению. Они более агрессивны. У них повышенная чувствительность в межличностных отношениях, ранимость, постоянное ощущение угрозы со стороны окружения. Это характерно для убийц. Преступники хуже чувствуют требования правовых и нравственных норм, которые не оказывают на них существенного влияния. Дезадаптация таких людей проявляется в том, что они не понимают, чего от них требует общество» [5, с. 7].

Иной особенностью личности, совершившей бытовое убийство, является наличие у подавляемого их большинства психических аномалий.

«В юридической литературе отсутствует четкая позиция по вопросу о понятии психической аномалии. Данное обстоятельство является основанием для споров и противоречивых выводов, в частности о том, что юридическое закрепление понятия психической аномалии неприемлемо. А между тем говорить о человеческой норме без учета ее оттенков представляется неверным, ибо оттенки нормы могут существенно влиять на уголовную ответственность лица, совершившего преступление и признанного вменяемым, на меры и средства профилактики, назначение наказания, на законодательный процесс» [13, с. 94].

Говоря в данной работе о психических аномалиях, имеются в виду лица с психическим расстройством, не исключающим вменяемости, которые подлежат уголовной ответственности (ст. 22 УК РФ).

Одни исследователи психическими аномалиями считают «временное расстройство душевной деятельности, слабоумие или иное болезненное состояние, хроническую душевную болезнь в фазе стойкой ремиссии, не исключающие способности обвиняемого отдавать себе отчет в своих действиях и руководить ими, т. е. отличающиеся от психических расстройств, исключающих вменяемость. К таковым расстройствам они относят дебильность, психопатию, хронический алкоголизм, эпилепсию, различные реактивные состояния, психофизический инфантилизм и др.» [6, с. 204]. 
Другие под психическими аномалиями понимают «реактивные, невротические, психопатические, суперсуггестивные состояния, умственную отсталость, акцентуации характера - повышенную тревожность, ригидность, агрессивность, конфликтность - имеющие опосредованную криминогенную значимость, модифицируя общую поведенческую схему личности» [11, с. 292-293].

Ц. А. Голумб под психическими аномалиями, не исключающими вменяемость, понимает «некоторые психические заболевания и патологические состояния психики либо другие расстройства нервно-психической деятельности, которые не достигли степени душевной болезни, лишающей данное лицо возможности отдавать себе отчет в своих действиях и в силу эмоционально-волевой или интеллектуальной патологии руководить ими в период совершения преступления» $[8$, с. 5].

Другой точки зрения придерживается Н. Г. Иванов. Он считает, что «под психическими аномалиями в широком смысле следует понимать все психические процессы, которые характеризуются дисбалансом сил возбуждения и сил торможения» [13, с. 20].

Ю. М. Антонян и М. В. Власова, позиции которых придерживается и автор настоящей статьи, психическими аномалиями считают «все расстройства психической деятельности, не достигшие психотического уровня и не исключающие вменяемости, но влекущие личностные изменения, которые могут привести к отклоняющемуся поведению» [2, с. 18].

«Психические аномалии способствуют формированию криминогенных взглядов, стремлений, ориентаций, потребностей и привычек. Они способствуют возникновению таких черт, как раздражительность, агрессивность, жестокость, снижению волевых процессов, ослаблению контрольных механизмов. Проведенные исследования показали, что только в отношении 15,7 \% от числа изученных осужденных нет сведений в уголовном деле о наличии у них психических аномалий. Обнаружены психические аномалии у 84,3 \% исследованных - это достаточно много. Такая распространенность, а точнее, столь существенная пораженность различными психическими аномалиями изученного контингента преступников и существенная разница по сравнению с группой всех лиц, совершивших тяжкие и особо тяжкие преступления против личности, позволяет сделать вывод о том, что наличие психических аномалий является устойчивым и характерным признаком для лиц, совершивших "семейные" убийства» [12, с. 14].

Наличие психических аномалий наиболее часто встречается именно у насильственных типов субъектов преступлений, к которым и относятся бытовые убийцы, поскольку, к примеру, при совершении отдельных корыстных преступлений требуется определенный уровень навыков, умений, 
предварительной подготовки, а в необходимых случаях - проработка детального плана совершения преступления, реализация которого лицом с психическими аномалиями затруднительна.

По мнению В.Н.Бурлакова, «психические аномалии наиболее часто встречаются среди лиц, совершающих тяжкие преступления против личности, несовершеннолетних преступников и рецидивистов. Психические аномалии воздействуют на поведение, в том числе преступное, не сами по себе, а через формирующее влияние на психологические особенности личности. Поэтому именно эти особенности, а не психические аномалии, следует признать криминогенными. Признание такого опосредованного влияния означает, что в первую очередь надлежащее воспитание и необходимые коррекционные социально-психологические мероприятия, а не медико-психиатрическое действие, способны оказать профилактическое воздействие» [7, с. 26-27]. В свою очередь, автор настоящей статьи склонен к тому, что в качестве профилактической составляющей на личность необходимо воздействовать и медико-психологическим методом, что, несомненно, принесет больший «оздоравливающий» эффект, а также привлекая для этого врачей-психиатров, в случае деформирования психической аномалии в устойчивое психическое расстройство.

«В юридической литературе в течение ряда лет недооценивались значение психических аномалий в механизме преступного поведения, а также необходимость учитывать этот механизм в индивидуализации ответственности и наказания. Судебные психиатры на протяжении многих лет, ведя вполне оправданную в методологическом плане борьбу с неоломброзианскими взглядами, нередко полностью игнорировали психические аномалии (в том числе и умственную неполноценность) как возможный источник опасных для общества действий. Ни на теоретическом, ни тем более на эмпирическом уровне не проводились исследования о возможном влиянии иных особенностей психики на формирование преступного поведения. Психофизиологические особенности субъекта, заключающиеся в дисбалансе динамических процессов, вообще не были предметом рассмотрения со стороны криминалистов. Был упущен большой пласт поведенческих детерминант, оказывающих влияние и на преступное поведение. Поэтому в судебно-медицинских и других документах, играющих важную роль в правоприменении, не фиксируются иные особенности психики, способные оказывать влияние на поведение субъекта» [13, с. 137].

Несомненно, при расследовании уголовного дела активную роль в этом играет следователь, путем назначения психолого-психиатрических экспертиз, поскольку именно на нем лежит обязанность по изучению личности обвиняемого на данной стадии уголовного судопроизводства. 
Проведенные Ю. М. Антоняном и М. В. Власовой исследования показали, что «в результате семейно-бытовых конфликтов - "семейные" убийства, по которым лица, его совершившие, имели психические аномалии, составляли около 38 \% от общего количества убийств. Как правило, лица, осужденные за такие преступления, страдали алкоголизмом и их преступные действия всегда связаны со злоупотреблением алкогольными напитками» [2, с. 20]. Как видно, данное исследование охватывает только часть бытовых убийств, а именно совершенных в семейно-бытовой сфере.

В целях сбора данных о психологических особенностях личности бытового убийцы, автором были изучены более 50 уголовных дел, рассмотренных судом за период с 2006 по 2014 гг. Следует отметить, что во внимание не принимались уголовные дела, в ходе расследования которых было установлено, что лицом было совершено общественно опасное деяние в состоянии невменяемости.

Проведенное исследование показало, что зеркальным отражением психологических особенностей личности бытового убийцы является тип наиболее опасных преступников, которых принято называть «серийными убийцами». В отличие от последних, бытовые убийства совершаются спонтанно, сиюминутно, при отсутствии какого-либо плана действий; к тому же, нередко такие действия провоцируются самими потерпевшими. Как правило, после совершения подобного преступления лицо, его совершившее, не пытается скрыть следы совершенного преступления, либо делает это неловко, второпях. Наличие «спонтанного» умысла приводит к тому, что бытовой убийца хватается за любые подручные предметы, которыми и причиняет потерпевшему смертельные ранения, не думая даже о том, что его действия очевидны другим находящимся поблизости лицам (собутыльникам, членам семьи, соседям, случайным прохожим и т. п.).

Таким образом, исходя из полученных в ходе исследования данных, можно привести следующие психологические особенности личности бытового убийцы, знание которых значительно упростит раскрытие и расследование данного вида преступлений:

- мужчина либо женщина в возрасте 25-50 лет. Как правило, в официальном браке не состоит, имеет детей, которые проживают отдельно (в результате лишения родительских прав);

- интеллект средний или ниже среднего, на состояние которого не в последнюю очередь оказало длительное злоупотребление спиртным; круг интересов сводится к тому, как достать деньги на спиртное, даже самого низкого качества. Отсутствует мотивировка к повышению образовательного уровня, все процессы познания окружающей действительности происходят на бытовом уровне, в привычной микросреде, участниками 
которой являются лица, близкие по образу жизни, мышлению, потребностям. Словарный запас, в силу вышеуказанного, ограничен, может быть насыщен нецензурными выражениями и жаргонизмами (в зависимости от наличия криминального опыта);

- занятость на низкоквалифицированной работе, в которой преобладает тяжелый физический труд либо вовсе длительное время отсутствует место работы; средства на существование в таких случаях достигаются случайными заработками. Как правило, происходит частая смена рабочих мест в результате систематических прогулов или появления на работе в состоянии алкогольного опьянения. Полученные в результате таких работ незначительные денежные средства расходуются на покупку спиртного либо незначительного количества продуктов питания;

- преобладает социальная дезадаптация, которая усугубляется вышеуказанными обстоятельствами, происходит общее деградирование личности, основные интересы сводятся к пьяным посиделкам, утрачивается (или изначально отсутствует) интерес к самообразованию, культурному обогащению, к заботе о своем здоровье, внешности, своих детях и близких: внешний вид неопрятен, одежда устарела, пренебрегаются правила личной гигиены. Данному лицу в результате длительного моральнонравственного разложения неважно, как он выглядит, что о нем думают окружающие его люди;

- совершение преступного действия без предварительной подготовки (наиболее характерно для лиц с психическими аномалиями), под влиянием внезапно нахлынувших эмоций, сиюминутных желаний, которые не в силах подавить аномальная психика убийцы. При этом в полной мере сохраняется контроль над своими действиями, лицо осознает их общественную опасность;

- преступление совершается с использованием первых попавшихся под руку предметов бытового окружения, обладающих колюще-режущими свойствами либо с твердой преобладающей поверхностью (нож, топор, хозяйственный инструмент, предмет мебели); реже для этого используется огнестрельное оружие. Количество нанесенных ударов может быть любым, но чаще всего они малочисленны и локализированы в местах расположения жизненно важных органов человека (головы, сердца, иных внутренних органов);

- редко принимаются меры к сокрытию следов совершенного преступления, трупа, орудия, своей одежды, видоизменению окружающей обстановки. В случае если такие действия все же совершаются, то только на «скорую руку», впопыхах, своей продуманностью не отличаются. К примеру, орудие совершенного преступления (нож, подручный предмет) остается 
либо на месте преступления, либо выбрасывается неподалеку (в окно, в мусорный бак); одежда, в которой совершалось преступление, остается на убийце, в ней он спокойно может продолжить дальнейшее застолье или лечь спать, не придавая особого значения тому, что на ней могут сохраниться следы совершенного преступления;

- внутреннее состояние после совершения преступления - опустошенное (в связи с устранением источника конфликта, агрессии), нередко происходит раскаяние в содеянном, возникает желание (как правило, на первоначальном этапе расследования) активного сотрудничества с правоохранительными органами (однако редко сами являются в правоохранительные органы), обосновать свои действия, переложить часть вины (по наступившим последствиям) на потерпевшего.

Приведенные психологические особенности личности бытового убийцы являются условными и содержат только общие, наиболее типичные признаки, которым отвечает рассматриваемая категория лиц, совершивших преступления.

В психологическую характеристику личности любого преступника, и бытового убийцы в частности, также входят его эмоциональные, волевые и интеллектуальные качества, каждые из которых в рассматриваемом контексте могут обладать своими особенностями.

К интеллектуальным свойствам относятся: жизненный опыт личности, уровень его знаний, навыков, способности к обучению и самообразованию. Как показывает практика, чаще всего лица, совершающие бытовые убийства, не имеют тяги к образовательному процессу, расширению своего кругозора, общему повышению интеллектуального уровня. Путь получения образования заканчивается, как правило, окончанием школы, в отдельных случаях - получением средне-специального образования. Данные ограничения обусловлены как наличием психических аномалий, отклонений, так и недостатками воспитательного процесса такой личности, педагогической запущенностью, родительским попустительством. Так, лицам с олигофренией в легкой ее степени (дебильности) с трудом дается воспитательный процесс, имеются сложности и в процессе запоминания. Тем не менее, это не лишает их способности выполнять трудовую функцию, не связанную с интеллектуальной деятельностью [18]. Такие лица, как правило, заняты тяжелым физическим низкооплачиваемым трудом, который не способен удовлетворить всех их потребностей. Низкий культурно-образовательный уровень, отсутствие стабильного заработка являются причинами совершения многих корыстных и корыстно-насильственных преступлений, не отличающихся особой изощренностью. Об этом свидетельствует и анализ практики расследованных уголовных дел о бытовых убийствах за 2007-2014 гг., 
который показал, что значительное количество осужденных за подобные преступления ранее совершали корыстные и корыстно-насильственные преступления.

Приведенные данные свидетельствуют об основополагающей роли семьи в становлении законопослушного гражданина, социально полезного члена общества. Низкие образовательный и интеллектуальный уровни прямо пропорциональны адаптационным возможностям субъекта, не оставляют ему широкого выбора сил и средств по разрешению сложившейся конфликтной ситуации, в связи с чем субъект прибегает к насильственному способу со всеми вытекающими отсюда последствиями.

«Эмоциональные свойства характеризуются внешним проявлением черт характера, степенью и скоростью эмоциональной возбудимости, особенностями протекания реакций на внешние раздражители. Условия становления и воспитания индивида формируют его нравственный и эмоциональный облик, накладывая на них свой неоспоримый отпечаток. Если чрезмерно сложная жизненная ситуация превышает приспособительные возможности индивида, происходит избыточное перевозбуждение его эмоциональной сферы. Избыточная энергетизация организма блокирует высшие регуляционные механизмы, приводит к соматическим нарушениям и нервным срывам. Поведение индивида при этом смещается на более низкие уровни регуляции» [11, с. 131]. У лиц, совершивших бытовые убийства, чаще, чем у здоровых людей, находят свое внешнее выражение отрицательные эмоции в виде гнева. Последний представляет собой очень сильную эмоциональную реакцию, которая возникает в ряде ситуаций, например, в случае физического насилия, причинения ущерба, лишения имущества, нападения или угроз и т. д. Гнев часто определяется (или, лучше сказать, идентифицируется) совокупностью физических реакций, включая определенную мимику, жесты, позы, характерные реакции вегетативной нервной системы [16]. При отсутствии каких-либо психических отклонений у здорового человека вспышки гнева протекают скрытно, по крайней мере, без явно выраженных двигательных реакций и проявлений актов агрессии [17]. Выход отрицательных эмоций происходит за счет вербального контакта либо двигательной реакции, направленной вовне или в иное безопасное русло. В случае психических аномалий вспышки гнева могут происходить неконтролируемо; при незначительном поводе, который носит деструктивный характер, реализуются в акты агрессии, приводящие к совершению бытовых убийств. Другие исходные эмоции, помимо гнева (радость, страх, удивление) у бытового убийцы (и иных субъектов преступлений, относящихся к насильственному типу) встречаются гораздо реже, но могут иметь смешанный характер. Таким образом, гнев можно 
определить как базовую эмоцию в структуре психологических свойств личности бытового убийцы.

Воля (англ. volition, will) представляет собой способность человека действовать в направлении сознательно поставленной цели, преодолевая при этом внутренние препятствия (т. е. свои непосредственные желания и стремления). Развитие воли начинается в раннем детстве и проходит длинный путь (возникновение действий, направленных на осуществление желания, избирательных действий; готовность поступить вопреки непосредственному эмоциональному побуждению; понимание «правил» поведения и т. д.) [15].

Волевые свойства включают в себя особенности принятия и реализации решений, их самостоятельности либо, наоборот, зависимости от воли других лиц. Волевая личность характеризуется стойкостью характера, настойчивостью в принятых решениях. Крайние ее проявления - жесткость или даже жестокость, и наоборот - покладистость и мягкость. Все волевые действия являются сознательными, в противном случае следует говорить о совершенном общественно опасном деянии в состоянии невменяемости.

Простые волевые действия состоят из трех структурных элементов: 1) мотив, совмещенный с целью; 2) исполнение действия; 3) оценка результата. Простые действия обычно не связаны со значительными волевыми усилиями и реализуются в форме навыков и привычек [10].

Основной личностной детерминантой любого поведения, в том числе и преступного, является мотив. Он оказывает значительное влияние на весь механизм преступного поведения и поэтому занимает в нем особое место.

Исполнение действия, как составляющая волевого акта, занимает центральное место в его структуре, поскольку оно по своей сути представляет собой объективную сторону наиболее общественно опасного состава преступления. При его осуществлении происходит полное осознание его преступности и наказуемости, однако волевым усилием внезапно возникший умысел воплощается в реальность.

Оценка результата может произойти уже гораздо позже момента совершения преступления и завершиться спустя длительное время, в том числе в ходе предварительного следствия.

«Семейное неблагополучие, как следует из рассказов опрошенных, заключалось в систематическом злоупотреблении спиртными напитками, ссорах и скандалах в семье, привычном разрешении конфликтов с помощью грубости и насилия, пренебрежительном отношении родителей к своим родительским обязанностям, совершении ими правонарушений. Разумеется, такая обстановка может разрушающе действовать на психику, приводить к деморализации детей и подростков, формировать особенности характера, которые потом могут повлечь за собой антиобщественное 
поведение. Это, в свою очередь, создает благоприятные предпосылки для возникновения или развития психических аномалий. Сама преступная деятельность, постоянное ведение антиобщественного образа жизни и связанное с ними длительное пребывание в местах лишения свободы способствуют возникновению и развитию патологических изменений в психике. Этот вывод основывается на том, что в возникновении и развитии таких аномалий, как психопатия, алкоголизм, черепно-мозговые травмы и реактивные состояния, очень велика роль антиобщественного образа жизни индивида, неблагоприятных условий его формирования и развития, особенно в детском и подростковом возрасте, прежде всего в семье, внешних социальных, в том числе психотравмирующих факторов в микроокружении» $[1$, с. 34-36].

Крайний эгоцентризм пронизывает все обыденное поведение таких людей. Все чаще и чаще возникает желание в удовлетворении своих сиюминутно возникших потребностей, не принимая во внимание мнение других. Проявление агрессии и, как следствие ее - насилия, является основной движущей силой для реализации своих стремлений, обходя и игнорируя общепринятые нормы морали и нравственности, в случае необходимости применяя для этого средства психологической защиты в виде перекладывания части или всей ответственности за наступившие последствия на самого потерпевшего, его провоцирующее поведение либо иные, не зависящие от действий обвиняемого обстоятельства. Как уже отмечалось, данные качества личности бытового убийцы формируются в условиях негативной семейной и социальной микросреды, при недостатке должного внимания и контроля над поведением ребенка, в чьем присутствии нередко происходят сцены семейного насилия, которые впоследствии будут являться обыденной моделью его преступного поведения, извращая истинное понимание социально одобряемых поступков. Личность в подобных случаях формируется при отсутствии нравственных примеров, поведение не корректируется в положительную сторону.

Таким образом, формирование личности будущего преступника, для которого жизнь человека не обладает какой-либо ценностью, и посягательство на нее является обыденным средством разрешения конфликта, осуществляется в детском возрасте, одновременно с формированием характера.

«Констатация какой-либо психической аномалии (например, психопатии и органического поражения центральной нервной системы) отнюдь не объясняет, почему данный человек совершил преступление. Мотивация преступного поведения не представлена в диагнозе, который лишь определяет наличие того или иного расстройства, его степень, тяжесть и т. д. Поэтому понять субъективные причины преступления, представленные в мотиве, 
можно лишь путем психологического исследования личности, ее мотивационных тенденций» [2, с. 36-37].

«Аномалии в психике способствуют возникновению и развитию таких отрицательных черт, как агрессивность, жестокость, раздражительность, приводят к снижению волевых процессов, повышению внушаемости, ослаблению сдерживающих контрольных механизмов. Эти негативные явления препятствуют нормальной социализации и воспитанию личности, ее трудовой деятельности, овладению новыми социальными ролями, установлению позитивных связей, формируют определенный уровень потребностей, интересов, ценностных ориентаций и соответствующий им образ жизни. При таких аномалиях легче воспринимаются и усваиваются антиобщественные воздействия; они мешают адекватному "толкованию" ситуации, предшествующей или сопутствующей преступлению, и в то же время облегчают вовлечение в преступную деятельность и реализацию преступных намерений» [2, с. 37].

На процесс формирования личности бытового убийцы влияет семья, которая, в данном случае, не оказала на него положительного влияния, не дала нужного воспитания. Как справедливо отмечено одним из исследователей данного вопроса, в качестве основополагающего фактора дефектности семейной социализации выступает деформация семейных связей и отношений, выражающаяся в структурной неполноценности семьи или в нарушении межличностных отношений ее членов. Структурная неполноценность характерна для большинства неблагополучных семей, являясь следствием нарушения межличностных связей и отношений между родителями [9].

Выход из конфликта предполагает наличие социально адаптированного сознания, нежелания прибегать к насилию, выбора (и осознания этого) иных сил и средств, пригодных для использования в конкретной жизненной ситуации. Лицо, выбравшее способ лишения чужой жизни единственно для себя приемлемым, ввиду ограниченности и узости своего сознания, не желает и не хочет выбирать другой способ, поскольку этот является для него наиболее действенным, сформированным в виде оптимальной модели поведения. Особую роль на пути нравственного воспитания играет образовательный процесс, поскольку именно он должен способствовать повышению культурного, интеллектуального, нравственного развития личности.

Слабые и несформировавшиеся адаптационные механизмы психики индивида, вызванные как недостатками воспитательного и образовательного процессов, так и иными сопутствующими факторами (социальными, экономическими), с высокой долей вероятности найдут свое проявление не только в виде принятия решения о насильственном способе разрешения конфликта, но и после освобождения из мест лишения свободы, что может сыграть свою печальную роль на пути исправления личности. 


\section{Литература}

1. Антонян Ю. М., Бородин С. В. Преступность и психические аномалии. М.: Наука, 1987.

2. Антонян Ю. М., Власова М. В. Предупреждение убийств, совершаемых лицами с психическими аномалиями: Монография. - М.: Изд-во ВНИИ МВД России, 2005.

3. Антонян Ю. М., Горшков И. В., Зулкарнеев Р.М. Проблемы внутрисемейной агрессии. - М.: Изд-во НИИ МВД РФ, 1999.

4. Антонян Ю. М., Еникеев М. И., Эминов В. Е. Психология преступника и расследования преступлений. - М.: Юрист, 1996.

5. Башкирский А. И. Психология личности преступника. Типология преступных личностей и мотивация преступного поведения. - Челябинск: Изд-во Челябинского юридического института МВД РФ, 1988.

6. Белкин Р. С. Криминалистическая энциклопедия. - М.: Мегатрон XXI, 2000.

7. Бурлаков В. Н. Криминогенная личность и индивидуальное предупреждение преступлений: проблемы моделирования. - СПб., 1998.

8. ГолумбЦ. А. Насильственные преступления, совершенные лицами с психическими аномалиями, и профилактика этих преступлений: автореф. дисс. ... канд. юрид. наук. - Л., 1982.

9. Гомонов Н. Д. Семейные дефекты социализации личности и преступное поведение // Криминология: вчера, сегодня, завтра: Труды СанктПетербургского криминологического клуба. - 2002. - № 1 (2).

10. Еникеев М. И. Юридическая психология. Краткий учебный курс. - М.: Норма, 2003.

11. Еникеев М.И. Юридическая психология. С основами общей и социальной психологии: Учебник для вузов. - М.: Норма, 2005.

12. Зулкарнеев Р. М. Предупреждение убийств членов семьи: дисс. ... канд. юрид. наук. - М., 1998.

13. Иванов Н. Г. Аномальный субъект преступления. - М., 1998.

14. Игогиев К. Е. Типология личности преступника и мотивация преступного поведения. - Горький, 1974.

15. Мещеряков Б. Г., Зинченко В. П. Большой психологический словарь. СПб.: Олма-пресс, 2004.

16. Ребер А. Оксфордский толковый словарь по психологии. - М., 2002.

17. Blair R. J. R. Neurobiological basis of psychopathy // British Journal of Psychiatry. - 2003. - P. 8.

18. Blair R. J.R. Neurocognitive models of aggression, the antisocial personality disorders, and psychopathy // Journal of Neurology, Neurosurgery and Psychiatry. - 2001. - P. 29. 
10. Abakumova I. V., Kruteleva L. Ju. Tolerance in the Structure of Life-Sense Strategies of the Modern Youth / The 13th European Congress of Psychology, 2013, Stockholm, Sweden, 9-12 July 2013.

11. Halpern D. Moral values, social trust and inequality // British Journal of Criminology, 2001, Vol. 41, pp. 236-251.

12. Leung K. Social axioms. The search for universal dimensions of general beliefs about how the world functions // J. of Cross-Cultural psychology, 2002, Vol. 33, pp. 286-302.

\section{THE USE OF PSYCHOLOGICAL KNOWLEDGE WHEN INVESTIGATING DOMESTIC HOMICIDES}

\section{Kiselev Aleksandr Petrovich}

This article touches upon urgent problems of law-enforcement practice for investigation of the most socially dangerous types of crimes - domestic homicides which form a considerable proportion of all the homicides committed in the territory of the Russian Federation.

Effective investigation of domestic homicides, realization of a complex of measures by authorized state bodies directed on prevention of such crimes is impossible without knowledge of psychological features of such a personality by the law enforcement official. The carried out scientific studying have made it possible to distinguish and generalize these features, to disclose their content.

The article explains psychological features of the person committed domestic homicide, gives opinions of scientists who have developed, studied and researched these spheres, specifies mental abnormalities, their significance and influence on the illegal behavior of the person committed domestic homicide. The author has made an attempt to indicate reasons which lead or may lead to commission of acts of aggression in a family and also designates other external circumstances, subjective factors influencing a choice of a violent way of resolving conflicts. Features of a domestic murderer's behavior after commission of a socially dangerous act are given.

The author uses not only empirical data, but also facts of the investigative and judicial practice which have made it possible to unite practical experience with psychological, criminological researches of personality, in relation to domestic homicides. In this regard, this article is of scientific and practical interest for the experts involved in investigation of domestic homicides and their prevention. 


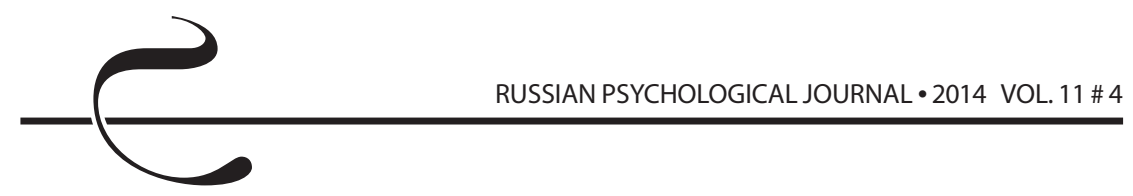

Keywords: domestic homicides, psychological features, mental abnormalities, personality, psycho-traumatic situation, conflict situation, aggression, motivation, needs, psychological characteristic.

\section{References}

1. Antonian lu. M., Borodin S.V. Prestupnost'i psikhicheskie anomalii [Criminality and mental abnormalities]. Moscow, Nauka Publ., 1987.

2. Antonian lu. M., Vlasova M.V. Preduprezhdenie ubiistv, sovershaemykh litsami spsikhicheskimi anomaliiami: Monografiia [Prevention of murders committed by persons with mental abnormalities. Monograph]. Moscow, the All-Russian Research Institute of the Interior Ministry of Russia Publ., 2005.

3. Antonian lu. M., Gorshkov I. V., Zulkarneev R. M. Problemy vnutrisemeinoi agressii [Problems of intra-family aggression]. Moscow, the All-Russian Research Institute of the Interior Ministry of Russia Publ., 1999.

4. Antonian lu. M., Enikeev M. I., Eminov V. E. Psikhologiia prestupnika i rassledovaniia prestuplenii [The psychology of the criminal and investigation of crimes]. Moscow, lurist Publ., 1996.

5. Bashkirskii A. I. Psikhologiia lichnosti prestupnika. Tipologiia prestupnykh lichnostei i motivatsiia prestupnogo povedeniia [The psychology of the criminal. Criminal persons' typology and motivation of criminal behavior]. Chelyabinsk, Chelyabinsk Institute of Legal Studies of the Interior Ministry of Russia Publ., 1988.

6. Belkin R. S. Kriminalisticheskaia entsiklopediia [Criminalistics encyclopaedia]. Moscow, Megatron XXI Publ., 2000.

7. Burlakov V. N. Kriminogennaia lichnost' $i$ individual'noe preduprezhdenie prestuplenii:problemy modelirovaniia [Criminogenic personality and individual prevention of crimes: modeling problems]. St. Petersburg, 1998.

8. Golumb Ts. A. Nasil'stvennye prestupleniia, sovershennye litsamis psikhicheskimi anomaliiami, i profilaktika etikh prestuplenii. Diss. cand. iurid. nauk [Violent crimes committed by persons with mental abnormalities and prevention of these crimes. Cand. jurid. sci. diss]. Leningrad, 1982.

9. Gomonov N. D. Semeinye defekty sotsializatsii lichnosti i prestupnoe povedenie// Kriminologiia: vchera, segodnia, zavtra: Trudy Sankt-Peterburgskogo kriminologicheskogo kluba [Family defects of socialization of personality and criminal behavior. Criminology: yesterday, today, tomorrow. Works of the St. Petersburg criminological club]. St. Petersburg, 2002, no. 1 (2).

10. Enikeev M. I. luridicheskaia psikhologiia. Kratkii uchebnyi kurs [Legal psychology. A brief tutorial]. Moscow, Norma Publ., 2003.

11. Enikeev M. I. Iuridicheskaia psikhologiia. S osnovami obshchei i sotsial'noi psikhologii: Uchebnik dlia vuzov [Legal psychology. With fundamentals of 
general and social psychology: textbook for institutes of higher education]. Moscow, Norma Publ., 2005.

12. Zulkarneev R. M. Preduprezhdenie ubiistv chlenov sem'i. Diss. cand. iurid. nauk [Prevention of murders of family members. Cand. jurid. sci. diss]. Moscow, 1998.

13. Ivanov N. G. Anomal'nyi sub"ekt prestupleniia [The abnormal subject of crime]. Moscow, 1998.

14. Igogiev K. E. Tipologiia lichnosti prestupnika i motivatsiia prestupnogo povedeniia [Typology of the criminal personality and motivation of criminal behavior]. Gorky, 1974.

15. Meshcheriakov B. G., Zinchenko V. P. Bol'shoi psikhologicheskii slovar' [Large psychology dictionary]. St. Petersburg, Olma-press Publ., 2004.

16. Reber A. Oksfordskii tolkovyi slovar' po psikhologii [Oxford explanatory dictionary of psychology]. Moscow, 2002.

17. Blair R. J. R. Neurobiological basis of psychopathy // British Journal of Psychiatry, 2003, P. 8.

18. Blair R. J. R. Neurocognitive models of aggression, the antisocial personality disorders, and psychopathy // Journal of Neurology, Neurosurgery and Psychiatry, 2001, P. 29. 